\title{
STAT4 activation in smokers and patients with chronic obstructive pulmonary disease
}

\author{
A. Di Stefano*, G. Caramori\#, A. Capelli*, I. Gnemmi*, F.L. Ricciardolo", T. Oates*, C.F. Donner*, \\ K.F. Chung ${ }^{\#}$, P.J. Barnes ${ }^{\#}$, I.M. Adcock ${ }^{\#}$
}

STAT4 activation in smokers and patients with chronic obstructive pulmonary disease. A. Di Stefano, G. Caramori, A. Capelli, I. Gnemmi, F.L. Ricciardolo, T. Oates, C.F. Donner, K.F. Chung, P.J. Barnes, I. M. Adcock. (C) ERS Journals Ltd 2004.

ABSTRACT: Activation of the transcription factor signal transducer and activator of transcription (STAT)-4 is critical for the differentiation of T-helper 1 cells/type-1 cytotoxic T-cells and the production of interferon (IFN)- $\gamma$.

Expression of STAT4, phospho-STAT4, IFN- $\gamma$ and T-box expressed in T-cells (Tbet) proteins in bronchial biopsies and bronchoalveolar lavage (BAL)-derived lymphocytes, obtained from 12 smokers with mild/moderate chronic obstructive pulmonary disease (COPD) (forced expiratory volume in one second (FEV1) $59 \pm 16 \%$ predicted), 14 smokers with normal lung function (FEV1 106 $\pm 12 \%$ pred) and 12 nonsmoking subjects (FEV1 $111 \pm 14 \%$ pred), was examined by immunohistochemistry and immunocytochemistry.

In bronchial biopsies of COPD patients, the number of submucosal phosphoSTAT4+ cells was increased $(240(22-406)$ versus $125(0-492)$ versus 29 (0-511) cells $\cdot \mathrm{mm}^{-2}$ ) when compared with both healthy smokers and control nonsmokers, respectively. In smokers, phospho-STAT4 + cells correlated with the degree of airflow obstruction and the number of IFN- $\gamma+$ cells. Similar results were seen in BAL (2.8 (0.2-5.9) versus $1.03(0.09-1.6)$ versus $0.69(0-2.3)$ lymphocytes $\left.\cdot \mathrm{mL}^{-1} \times 10^{3}\right)$. In all smokers who underwent lavage, phospho-STAT4+ lymphocytes correlated with airflow obstruction and the number of IFN $\gamma+$ lymphocytes. T-bet expression was not altered in bronchial biopsies and BAL-derived lymphocytes between the three groups.

In conclusion, this study suggests that stable mild/moderate chronic obstructive pulmonary disease is associated with an active T-helper 1 cell/type-1 cytotoxic T-cell inflammatory process involving activation of signal transducer and activator of transcription $\mathbf{4}$ and interferon-gamma production.

Eur Respir J 2004; 24: 78-85.
*Salvatore Maugeri Foundation, IRCCS, Medical Centre of Rehabilitation, Division of Pulmonary Disease, Veruno, and OspedaliRiuniti, Bergamo, Italy. " Dept of Thoracic Medicine, National Heart and Lung Institute, Imperial College of London, London, UK.

Correspondence: I.M. Adcock, Dept of Thoracic Medicine, National Heart and Lung Institute, Imperial College of London, Dovehouse Street, London, SW3 6LY, UK.

Fax: 442073518126

E-mail: ian.adcock@imperial.ac.uk

Keywords: Airway inflammation

chronic obstructive pulmonary disease signal transducer and activator of transcription 4

T-bet

T-helper 1 cells/type-1 cytotoxic T-cells

T-lymphocytes

Received: July 102003

Accepted after revision: March 142004

This work was supported by the Associazione per la Ricerca e la Cura dell'Asma (ARCA; Padova, Italy), Salvatore Maugeri Foundation, IRCCS, "Ricerca Corrente" and GlaxoSmithKline (UK).
Chronic obstructive pulmonary disease (COPD) can be defined as "a disease state characterised by airflow limitation that is not fully reversible. The airflow limitation is usually both progressive and associated with an abnormal inflammatory response of the lungs to noxious particles or gases" [1]. Cigarette smoking is the major risk factor for the development of COPD and cigarette smokers constitute $>90 \%$ of COPD patients in developed countries $[1,2]$. Previous studies performed on bronchial biopsies from patients with COPD have reported an increased infiltration of CD3+ lymphocytes, with a decreased ratio of $\mathrm{CD} 4+/ \mathrm{CD} 8+$ cells and macrophages [3]. More recently, increased expression of C-C chemokine receptor (CCR) 5 in bronchial biopsies [4] and CXC chemokine receptor (CXCR)3 in the peripheral airways [5] of mild/ moderate COPD patients has been reported. Furthermore, double-stained cells co-expressing CXCR3/interferon (IFN)- $\gamma$ were found in bronchial biopsies from six COPD patients and two subjects with sarcoidosis, although a comparison with control groups was not performed [6]. These data are suggestive of an increased T-helper (Th)1 cell/type-1 cytotoxic $\mathrm{T}$-cell $(\mathrm{Tc} 1)$ inflammatory response, since the expression of

For editorial comments see page 3. these chemokine receptors (CCR5 and CXCR3) are reported to be mainly expressed on Th1-polarised T-cells [7].

Interleukin (IL)-12-mediated induction of IFN- $\gamma$ expression is regulated by the transcription factors signal transducer and activator of transcription (STAT) 4 and T-box expressed in T-cells (T-bet) in Thl cells [8]. Phosphorylation of STAT4 on tyrosine (Y)-693 is crucial for STAT4 activation and translocation to the nucleus [9]. In contrast, T-bet can specify Th1 effector fate by targeting chromatin remodelling to individual IFN- $\gamma$ alleles and inducing IL-12 receptor $\beta_{2}$ expression, without apparent assistance from IL-12/STAT4 $[10,11]$. This suggests that the regulation of IFN- $\gamma$ expression can be controlled by distinct transcriptional mechanisms, involving STAT4 or T-bet proteins separately. Changes in STAT4 and T-bet expression have not been investigated either in "suspected" Th1/Tc1 human lung diseases, such as COPD, or in better established Th1/Tcl diseases, such as sarcoidosis.

The aim of this study was to quantify the presence of IFN$\gamma+$ cells, and of cells expressing STAT4 and T-bet in bronchial biopsies, and to quantify bronchoalveolar lavage (BAL)derived lymphocytes expressing these proteins in patients with stable mild/moderate COPD. This will determine whether 
there is: 1) a predominant Th1/Tc1 profile in this disease; and 2) an involvement of the transcription factors STAT4 and Tbet in IFN- $\gamma$ expression in COPD. Therefore, the current authors identified and quantified the number of cells expressing IFN- $\gamma$, STAT4, phospho-(Y-693)STAT4 and $\mathrm{T}$-bet proteins in bronchial biopsies, and the number of lymphocytes expressing the same proteins in the BAL from mild/moderate COPD patients, a control group of smokers and a group of nonsmokers with normal lung function. In bronchial biopsies, the current authors also quantified the percentage of T-cell subsets (CD4+ and CD8+) and macrophages (CD68+) co-expressing phospho-(Y-693)STAT4 in the submucosa of mild/moderate COPD patients. To the authors' knowledge, this is the first systematic analysis of IFN- $\gamma$ production and the transcription factors regulating its expression in patients with COPD.

\section{Methods}

\section{Subjects}

Bronchial biopsies were obtained from 38 subjects: 12 smokers had mild to moderate COPD (forced expiratory volume in one second (FEV1)/forced vital capacity (FVC) ratio $<70 \%$ and $\mathrm{FEV} 1>30 \%$ predicted) [1]; and 14 smokers had normal lung function $(\mathrm{FEV} 1 / \mathrm{FVC}$ ratio $>70 \%$ ) (table 1$)$. Where adequate samples were obtained, further immunocytochemical analysis was performed on BAL cytospins from seven nonsmoking control subjects, seven smokers with normal lung function and eight COPD patients (FEV1 mean \pm SD $\%$ pred: $118 \pm 17$ versus $104 \pm 18$ versus $71 \pm 8$, respectively; $\mathrm{p}<0.05$ COPD patients compared with control smokers and control nonsmokers).

None of the study subjects had suffered a recent exacerbation, defined as increased dyspnoea associated with a change in quality and quantity of sputum that would have led them to seek medical attention during the month preceding the study [1]. All subjects were free of acute upper respiratory tract infections, and none had received glucocorticoids, theophylline or antibiotics within the preceding month. All subjects were nonatopic, i.e. they had negative skin tests for common allergen extracts, and had no past history of asthma or allergic rhinitis.

Each subject underwent interview, chest radiography, electrocardiogram, routine blood test, skin tests with common allergen extracts and pulmonary-function tests, 2-5 days before bronchoscopy. The study conformed to the Declaration of Helsinki and informed consent was obtained from each subject. Bronchial biopsies and BAL were performed according to the local Ethics Committee Guidelines.

\section{Lung-function tests and volumes}

Pulmonary-function tests included measurements of FEV1 and FVC under baseline conditions in all the study subjects
(6200 Autobox Pulmonary Function Laboratory; Sensormedics Corp, Yorba Linda, CA, USA). The predicted normal values used were those from the Communité Européenne du Charbon et de 1'Acier [12]. In order to assess the reversibility of the airway obstruction, the FEV1 measurement, in the group of subjects with FEV $1<80 \%$ pred, was repeated $30 \mathrm{~min}$ after the inhalation of $400 \mu \mathrm{g}$ of salbutamol.

\section{Fibreoptic bronchoscopy, collection and processing of bronchial biopsies}

This was performed exactly as described previously $[13,14$, 15]. Four bronchial mucosal biopsy specimens were taken from segmental and subsegmental airways of the right lower and upper lobes, using size-19 cupped forceps. Bronchial biopsies for immunohistochemistry were processed as described later.

\section{Processing of bronchoalveolar lavage}

BAL was performed and processed as previously described [13]. Cytospin slides (Cytospin II; Shandon, London, UK), prepared with native pellet, were stained with May-Grunwald Giemsa to determine the leukocyte differential cell count. At least 500 cells (excluding epithelial cells) per slide were examined at $\times 1,000$ magnification. The cytospin slides used for immunocytochemistry were fixed for 2 min with acetone and frozen at $-80^{\circ} \mathrm{C}$ until their analysis.

\section{Immunohistochemistry (single- and double-staining)}

Biopsy specimens were gently extracted from the forceps, processed for light microscopy, as previously described, and stored frozen at $-80^{\circ} \mathrm{C}$ until use [13]. Two $6-\mu \mathrm{m}$ cryostat sections at an interval of $100 \mu \mathrm{m}$ were subsequently processed for immunohistochemistry, using the following panel of antibodies: mouse anti-CD3 (1:50, M0756; Dako Ltd, Cambridge, UK); mouse anti-CD4 (1:20, M0716; Dako Ltd); mouse anti-CD8 (1:20, M0707; Dako Ltd); mouse anti-CD68 (1:200, M0814; Dako Ltd); rabbit anti-STAT4 (1:300, sc-486; Santa Cruz Biotechnology, Wembley, UK); rabbit antiphospho-(Y-693)STAT4 (1:200, 71-7900; Zymed Laboratories Inc., Cambridge, UK); rabbit anti-T-bet (1:50, 523567; Zymed Laboratories Inc.); and mouse anti-IFN- $\gamma$ (1:100, MAB 2851; R\&D Systems, Abingdon, UK). Primary antibodies were revealed as previously described [15]. Doublestaining was performed with the rabbit anti-phospho-(Y693)STAT4 protein and mouse anti-CD4, CD8, CD68 and IFN- $\gamma$ antibodies. Control slides were included in each staining run, using human tonsil as a positive control for all the immunostaining performed. All antibodies were used at

Table 1.-Characteristics of subjects

\begin{tabular}{lccccccc}
\hline & $\begin{array}{c}\text { Subjects } \\
\mathrm{n}\end{array}$ & $\begin{array}{c}\text { Age } \\
\text { yrs }\end{array}$ & $\begin{array}{c}\text { Sex } \\
\text { M/F }\end{array}$ & $\begin{array}{c}\text { Smoking history } \\
\text { pack-yrs }\end{array}$ & $\begin{array}{c}\text { FEV1 } \\
\% \text { pred }\end{array}$ & $\begin{array}{c}\text { FEV1/FVC } \\
\%\end{array}$ & $\begin{array}{c}\Delta \text { FEV1 post-salbutamol } \\
\% \text { baseline }\end{array}$ \\
\hline Control nonsmokers & 12 & $61 \pm 11$ & $6 / 6$ & 0 & $111 \pm 14$ & $85 \pm 5$ & \\
Control smokers & 14 & $60 \pm 6$ & $12 / 2$ & $39 \pm 23$ & $106 \pm 12$ & $82 \pm 6$ & $57 \pm 8^{\#}$ \\
Mild/moderate COPD & 12 & $64 \pm 9$ & $10 / 2$ & $46 \pm 30$ & $59 \pm 16^{\#}$ & $5 \pm 4$ \\
\hline
\end{tabular}

Data are presented as $\mathrm{n}$ or mean $\pm \mathrm{SD}$. COPD: chronic obstructive pulmonary disease; M: male; F: female; FEV1: forced expiratory volume in one second; FVC: forced vital capacity. ${ }^{\#}: \mathrm{p}<0.0001$, significantly different from control smokers and control nonsmokers. 
1:50 dilution. Double-staining was performed in three representative COPD patients.

Light-microscopic analysis of stained cells in the epithelium and submucosa was performed at a magnification of $\times 900$. STAT4 and phospho-(Y-693)STAT4 were quantified as number of immunostained epithelial cells per $\mathrm{mm}$ of intact epithelium. IFN- $\gamma$ immunopositivity of intact epithelium was scored from 0 (absent) to 3 (all epithelial cells immunostained). Morphometric measurements were performed with a light microscope (Leitz Biomed; Leica, Cambridge, UK) linked to a computerised image system (Quantimet 500 Image Processing and Analysis System, Software Qwin V0200B; Leica).

\section{Immunocytochemistry}

The expression of STAT4, phospho-(Y-693)STAT4, T-bet and IFN- $\gamma$ in BAL-derived lymphocytes was assessed by immunocytochemistry on at least one cytospin for each subject. The primary antibodies anti-STAT4, anti-phospho(Y-693)STAT4, anti-T-bet and anti-IFN- $\gamma$ were used as previously described for bronchial biopsies. A mean \pm SD of $39 \pm 14$ total lymphocytes, identified on the basis of a morphologic criterion, was counted for each subject.

\section{Western blot analysis for STAT4 and phospho-STAT4}

Whole-cell proteins were extracted from bronchial biopsies as previously described [16]. At least $30 \mu \mathrm{g} \cdot \mathrm{lane}^{-1}$ of wholecell proteins were subjected to electrophoresis. Filters were incubated with rabbit anti-STAT4 (sc-486; Santa Cruz Biotechnology) for STAT4 protein or rabbit anti-phospho(Y-693)STAT4 (71-7900; Zymed Laboratories Inc.) for phospho-(Y-693)STAT4. The 43-kDa (actin) or 95-kDa (STAT4 and phospho-(Y-693)STAT4) bands were quantified using densitometry with Grab-It and GelWorks software (UVP, Cambridge, UK) and expressed as a ratio.

\section{Data analysis}

Group data were expressed as mean \pm sD for functional data or median (range) for morphologic data. Differences between groups were analysed using analysis of variance (ANOVA) for functional data. Morphologic data were analysed by Kruskal Wallis test followed, when significant, by MannWhitney U-test for comparison between groups. Correlation coefficients were calculated using Spearman's rank method. Probability values of $\mathrm{p}<0.05$ were considered as significant.

\section{Results}

\section{Clinical findings}

The clinical characteristics of the subjects included in the study are reported in table 1 . As expected from the selection criteria, the values of FEV1 \% pred and FEV1/FVC ratio \% were significantly different in the group with COPD, as compared to both healthy smokers and control nonsmokers (ANOVA: $\mathrm{p}<0.0001$ ). BAL was performed in a subset of eight COPD patients, seven control smokers and seven control nonsmokers. The clinical characteristics of these subjects are reported in table 2 . No differences in BAL lymphocyte counts were seen in the three groups of subjects.

\section{CD3, CD4, CD8 and CD68 immunohistochemistry in the bronchial submucosa}

Quantification of inflammatory cells and transcription factors in bronchial biopsies is summarised in table 3 . The number of CD3 and CD8 immunoreactive cells was significantly increased in the submucosa of COPD patients and smokers with normal lung function, compared with nonsmoking subjects with normal lung function (table 3 ). In addition, the number of CD68 immunoreactive cells was

Table 2. - Characteristics of subjects who performed bronchoalveolar lavage

\begin{tabular}{lccccccc}
\hline & $\begin{array}{c}\text { Subjects } \\
\mathrm{n}\end{array}$ & $\begin{array}{c}\text { Age } \\
\text { yrs }\end{array}$ & $\begin{array}{c}\text { Sex } \\
\text { M/F }\end{array}$ & $\begin{array}{c}\text { Smoking history } \\
\text { pack-yrs }\end{array}$ & $\begin{array}{c}\text { FEV1 } \\
\% \text { pred }\end{array}$ & $\begin{array}{c}\text { FEV1/FVC } \\
\%\end{array}$ & $\begin{array}{c}\Delta \text { FEV1 post-salbutamol } \\
\% \text { baseline }\end{array}$ \\
\hline Control nonsmokers & 7 & $58 \pm 7$ & $4 / 3$ & 0 & $118 \pm 17$ & $87 \pm 7$ & \\
Control smokers & 7 & $56 \pm 10$ & $5 / 2$ & $28 \pm 10$ & $104 \pm 18$ & $81 \pm 6$ & \\
Mild/moderate COPD & 8 & $69 \pm 5^{* *}$ & $8 / 0$ & $40 \pm 15$ & $71 \pm 8^{* *}$ & $67 \pm 7^{* *}$ & $4 \pm 4$ \\
\hline
\end{tabular}

Data are expressed as $\mathrm{n}$ and mean $\pm \mathrm{SD}$. COPD: chronic obstructive pulmonary disease; M: male; F: female; FEV1: forced expiratory volume in one second; FVC: forced vital capacity. ${ }^{* *}: \mathrm{p}<0.01$, significantly different from control smokers and control nonsmokers.

Table 3.-Quantification of inflammatory cells, transcription factors and interferon (IFN)- $\gamma$ immunoreactive cells in the bronchial submucosa

\begin{tabular}{|c|c|c|c|c|}
\hline & Mild/moderate COPD & Control smokers & Control nonsmokers & $\mathrm{p}$-value \\
\hline CD3 & $586(122-1067)^{\bullet}$ & $467(180-1139)^{\bullet}$ & $320(168-582)$ & 0.03 \\
\hline CD4 & $271(127-654)$ & $205(37-368)$ & $172(88-310)$ & 0.09 \\
\hline CD8 & $223(163-409)^{\circ}$ & $291(93-571)^{\bullet}$ & $114(59-286)$ & 0.0065 \\
\hline CD68 & $702(399-833)^{\bullet}$ & $520(261-945)$ & $412(235-654)$ & 0.0066 \\
\hline Nuclear STAT4 & $114(0-353)$ & $42(0-198)$ & $0(0-218)$ & 0.063 \\
\hline Cytoplasm STAT4 & $242(150-705)$ & $242(99-441)$ & $176(40-500)$ & 0.42 \\
\hline Total STAT4 & $411(286-808)$ & $292(99-553)$ & $243(40-579)$ & 0.088 \\
\hline Phospho-(Y-693)STAT4 & $240(22-406)^{\#}$ & $125(0-492)$ & $29(0-511)$ & 0.037 \\
\hline T-bet & $34(22-67)$ & $32(3-89)$ & $21(4-137)$ & 0.56 \\
\hline IFN- $\gamma$ & $38(12-71)^{\bullet}$ & $29(0-115)$ & $10(0-46)$ & 0.05 \\
\hline
\end{tabular}

Data are presented as cells per $\mathrm{mm}^{2}$ median (range), unless otherwise stated. STAT4: signal transducer and activator of transcription 4; COPD: chronic obstructive pulmonary disease. ${ }^{\#}$ : significantly different from control smokers; ": significantly different from control nonsmokers. 

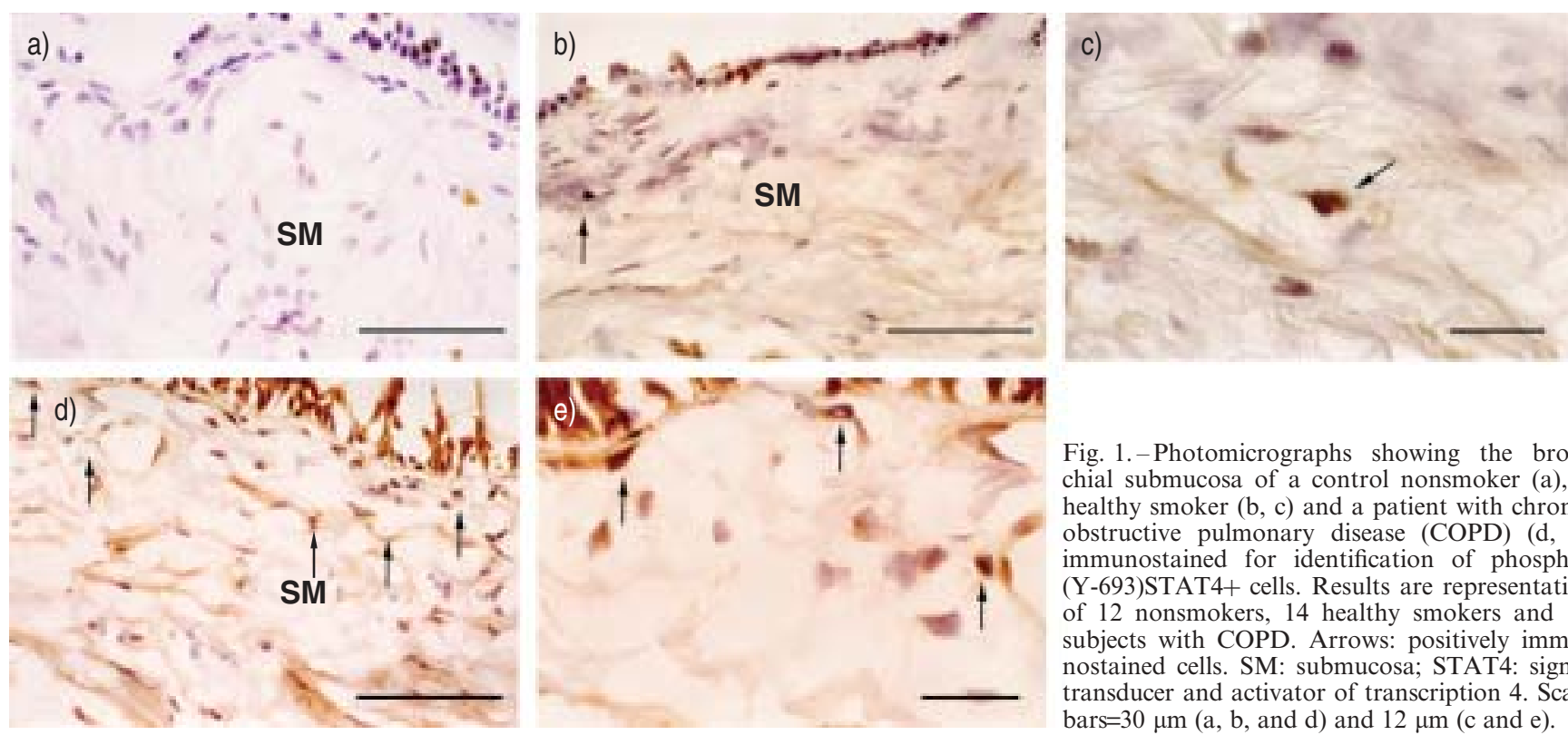

Fig. 1.-Photomicrographs showing the bronchial submucosa of a control nonsmoker (a), a healthy smoker (b, c) and a patient with chronic obstructive pulmonary disease (COPD) (d, e) immunostained for identification of phospho(Y-693)STAT4+ cells. Results are representative of 12 nonsmokers, 14 healthy smokers and 14 subjects with COPD. Arrows: positively immunostained cells. SM: submucosa; STAT4: signal transducer and activator of transcription 4. Scale bars $=30 \mu \mathrm{m}(\mathrm{a}, \mathrm{b}$, and $\mathrm{d})$ and $12 \mu \mathrm{m}$ (c and e).

significantly higher in COPD patients, compared with nonsmoking subjects.

\section{STAT4, phospho-STAT4, T-bet and IFN- $\gamma$ immunohistochemistry in the bronchial submucosa}

The number of phospho-(Y-693)STAT4-positive cells was significantly increased in COPD patients, in comparison to smokers with normal lung function (Mann Whitney: $\mathrm{p}=0.01$ ), and just failed to reach significance, compared to nonsmoking subjects (Mann Whitney: $\mathrm{p}=0.06$ ) (table 3, fig. 1). The increase in activated STAT4 did not merely reflect the increase in T-cells seen in COPD, as the increase in total cells expressing activated STAT4 was greater than the increase in CD3 + cells in COPD patients (table 3 ).

In contrast, the number of cells showing inactive cytoplasmic STAT4 or T-bet immunoreactivity did not differ significantly between the three groups of subjects examined (table 3). However, the number of IFN- $\gamma$ immunoreactive cells was significantly increased in patients with COPD, in comparison to nonsmoking subjects (Mann Whitney: $\mathrm{p}=0.008)$, but not in smokers with normal lung function (table 3).

Double-staining immunohistochemistry in the bronchial submucosa

Approximately half CD4+ (mean \pm SD: $50 \pm 7 \%$ ), one third of CD8+ $(33 \pm 4 \%)$ and one third of CD68+ $(30 \pm 8 \%)$ cells coexpressed phospho-(Y-693)STAT4 (fig. 2a, b and c, respectively). Furthermore, $64 \pm 15 \%$ of IFN- $\gamma+$ cells co-expressed the phospho-(Y-693)STAT4 protein (fig. 2d).

\section{STAT4, phospho-STAT4 and IFN- $\gamma$ immunohistochemistry in the bronchial epithelium}

The total number of STAT4-immunoreactive bronchial epithelial cells was significantly increased in smokers with COPD (412 cells $\left.\cdot \mathrm{mm}^{-1}(300-680)\right)$, compared with smokers with normal lung function (367 cells $\cdot \mathrm{mm}^{-1}$ (88-567); Mann
Whitney: $\mathrm{p}<0.05)$ and nonsmoking subjects with normal lung function ( 256 cells $\cdot \mathrm{mm}^{-1}$ (133-444); Mann Whitney: $\left.\mathrm{p}<0.05\right)$ A trend towards increased immunoreactivity of bronchial epithelial cells for phospho-STAT4 protein in COPD patients (450 cells $\left.\cdot \mathrm{mm}^{-1}(203-500)\right)$, control smokers $\left(333 \mathrm{cells} \cdot \mathrm{mm}^{-1}\right.$ (134-381)) and control nonsmokers $\left(310\right.$ cells $\cdot \mathrm{mm}^{-1}$ (123-412)) did not reach significance (Kruskal Wallis: $\mathrm{p}=0.06$ ).

Total STAT4 and phospho-(Y-693)STAT4 proteins were below the detection limits for Western blotting (data not shown). This was in contrast with data seen previously for other transcription factors, such as GATA3 [17] and nuclear factor- $\kappa \mathrm{B}$ [18], and possibly reflects the enhanced sensitivity of immunohistochemistry compared with Western blotting.
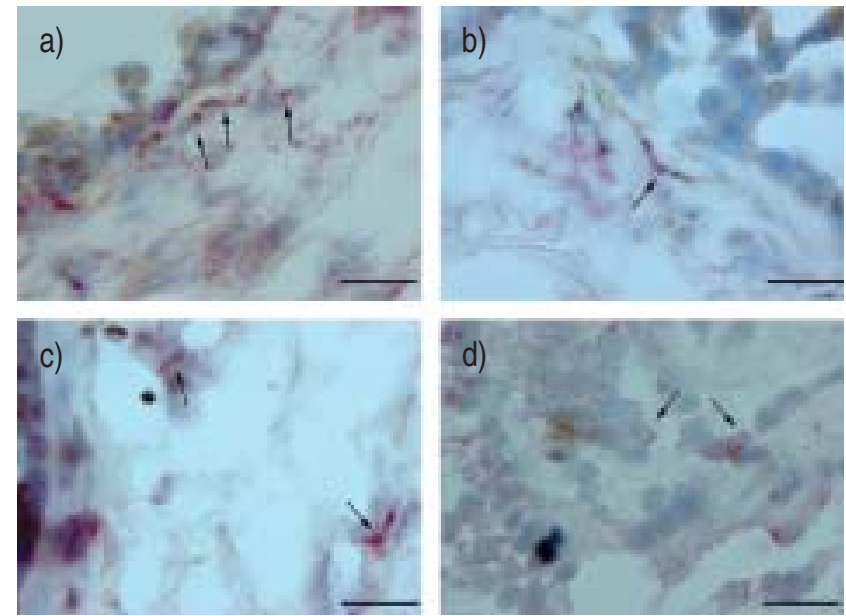

Fig. 2. - Photomicrographs showing double-staining in the bronchial submucosa of patients with chronic obstructive pulmonary disease (COPD). a) CD4+ phospho-(Y-693)STAT4+ cells, b) CD8+ phospho-(Y-693)STAT4+ cells, c) CD68+ phospho-(Y-693)STAT4+ cells and d) interferon (IFN)- $\gamma+$ phospho-(Y-693)STAT4+ cells in representative subjects with mild/moderate COPD. CD4+, CD8+, CD68+ and IFN- $\gamma$ revealed by fast red substrate (red colour), phospho-(Y693)STAT4 revealed by diaminobenzidine (brown colour). Arrows indicate positively immunostained cells. STAT4: signal transducer and activator of transcription 4 . Scale bars $=20 \mu \mathrm{m}$. 
Table 4.-Quantification of transcription factors and interferon (IFN)- $\gamma$ immunoreactive lymphocytes (Ly) in the bronchoalveolar lavage

\begin{tabular}{|c|c|c|c|c|}
\hline & Mild/moderate COPD & Control smokers & Control nonsmokers & p-value \\
\hline $\mathrm{Ly} \cdot \mathrm{mL}^{-1} \times 10^{3}$ & $11(3-101)$ & $5.2(1.4-7.1)$ & $4.1(0.9-17)$ & 0.30 \\
\hline Ly $\%$ & $4(1-35)$ & $1.9(0.8-3.8)$ & $4.3(0.9-12)$ & 0.077 \\
\hline $\mathrm{STAT} 4+\mathrm{Ly} \cdot \mathrm{mL}^{-1} \times 10^{3}$ & $6.7(1.9-9.8)^{*}$ & $2.3(0-4.1)$ & $1.2(0.3-5.1)$ & 0.017 \\
\hline Phospho-STAT4 $+\mathrm{Ly} \cdot \mathrm{mL}^{-1} \times 10^{3}$ & $2.8(0.2-5.9)^{*}$ & $1.03(0.09-1.6)$ & $0.69(0-2.3)$ & 0.012 \\
\hline $\mathrm{T}$-bet $+\mathrm{Ly} \cdot \mathrm{mL}^{-1} \times 10^{3}$ & $1.5(0-7.1)$ & $0.6(0-1.1)$ & $0.49(0-2.99)$ & 0.21 \\
\hline $\mathrm{IFN}-\gamma+\mathrm{Ly} \cdot \mathrm{mL}^{-1} \times 10^{3}$ & $2.5(0.3-5)$ & $1.2(0.4-2.1)$ & $0.9(0.24-7.9)$ & 0.43 \\
\hline STAT4+ Ly \% & $60(6-68)$ & $60(0-80)$ & $30(8-57)$ & 0.14 \\
\hline Phospho-STAT4+ Ly \% & $27(3-68)$ & $17(3-74)$ & $18(0-42)$ & 0.65 \\
\hline T-bet+ Ly $\%$ & $10(0-45)$ & $15(0-33)$ & $12(0-73)$ & 0.96 \\
\hline IFN- $\gamma+$ Ly $\%$ & $25(4-36)$ & $30(14-35)$ & $23(10-57)$ & 0.64 \\
\hline
\end{tabular}

Data are presented as median (range), unless otherwise stated. STAT4: signal transducer and activator of transcription 4; COPD: chronic obstructive pulmonary disease. *: $\mathrm{p}<0.05$, significantly different from control smokers and control nonsmokers.

\section{STAT4, phospho-STAT4, T-bet and IFN- $\gamma$ immunocytochemistry in the bronchoalveolar lavage}

The number of STAT4 and phospho-(Y-693)STAT4 immunoreactive lymphocytes in BAL was significantly increased in COPD patients, compared with both control groups (table 4). The number of T-bet + and IFN- $\gamma+$ lymphocytes in the recovered fluid (number of cells per $\mathrm{mL}$ of recovered fluid), as well as the percentage of STAT4+, phospho-STAT4+, T-bet+ and IFN- $\gamma+$ lymphocytes, did not differ significantly in the three groups of subjects studied (table 4).

\section{Correlations between structural and lung functional data}

When analysed across all smokers (either with normal lung function or with COPD), the number of phospho-(Y693)STAT4 immunoreactive cells in the submucosa was inversely correlated with the FEV1 \% pred ( $r=-0.46, \mathrm{p}<0.05$; fig. 3a) and was also correlated with the number of IFN- $\gamma$ immunoreactive cells $(r=0.45, p<0.05$; fig. $3 b)$. The current authors also observed a significant positive correlation between the number of nuclear STAT4+ cells and CD3+ cells $(\mathrm{r}=0.42, \mathrm{p}<0.05$; fig. $3 \mathrm{c})$, nuclear STAT4+ cells and CD4+ cells ( $\mathrm{r}=0.40, \mathrm{p}<0.05$; fig. $3 \mathrm{~d}$ ), total STAT4+ cells and CD3+ cells $(r=0.46, p<0.05)$, total STAT4+ cells and CD4+ cells $(\mathrm{r}=0.47, \mathrm{p}<0.05)$, total STAT4+ cells and CD68+ cells $(\mathrm{r}=0.53, \mathrm{p}<0.01)$, phospho-(Y-693)STAT4+ cells and CD68+ cells $(\mathrm{r}=0.54, \mathrm{p}<0.01$; fig. $3 \mathrm{e})$ and numbers of IFN- $\gamma+$ cells and CD68+ cells ( $\mathrm{r}=0.47, \mathrm{p}<0.05$; fig. $3 \mathrm{f})$.

In all smokers, the number of phospho-(Y-693)STAT4 and IFN- $\gamma$ immunoreactive lymphocytes were inversely correlated with FEV1 \% pred ( $\mathrm{r}=-0.62, \mathrm{p}<0.02$ and $\mathrm{r}=-0.58, \mathrm{p}<0.05$, respectively; fig. $4 \mathrm{a}$ and b). Furthermore, phospho-(Y693)STAT4 immunoreactivity correlated with IFN- $\gamma$ immunoreactivity ( $\mathrm{r}=0.57, \mathrm{p}<0.05$; fig. $4 \mathrm{c})$.

\section{Discussion}

To the best of the authors' knowledge, this study shows, for the first time, that in the bronchial biopsies of smokers with mild/moderate COPD there is an increased number of IFN$\gamma+$ cells, compared with control nonsmokers, and increased presence of activated STAT4+ cells, in comparison with smokers with normal lung function. The presence of activated STAT4+ cells is significantly associated with the presence of IFN- $\gamma+$ cells in both bronchial biopsies and BAL-derived lymphocytes, and correlates with the degree of airflow limitation in smokers. These data suggest the presence of an active Th1/Tc1-mediated inflammatory process in patients with stable mild/moderate COPD.

CD4+/CD8+ Th and CD4+/CD8+ Tc cells can be divided into two major subsets termed Th1/Tc1 and Th2/Tc2, respectively, based on the pattern of cytokines they produce [19]. Th1/Tc1 cells produce IFN- $\gamma$ and Th2/Tc 2 cells produce IL-4. STAT4-knockout mice have markedly impaired IFN- $\gamma$ production and Th1 differentiation, implicating an important role for STAT4 in the actions of IFN- $\gamma[20,21]$. IL-12 stimulation activates STAT4 by tyrosine phosphorylation of Y693, and subsequent STAT4 nuclear translocation is a crucial intermediate step for IFN- $\gamma$ gene induction in human T-cells and macrophages [9]. IFN- $\alpha$ and $-\beta$ can also activate STAT4 in human T-cells [22]; although, this is through a different pathway than that reported for IL-12 induction [9, 22]. In addition, T-cell receptor (TCR) engagement is also capable of activating STAT4 and inducing subsequent Th1/ Tc1 differentiation [22]. Thus, IL-12/STAT4 serves two essential functions in the development of Th1 cells: as a growth signal, inducing survival and cell division; and as a transactivator, prolonging IFN- $\gamma$ synthesis $[10,11,23]$.

The current authors have confirmed previous studies showing increased T-lymphocyte expression in bronchial biopsies and BAL samples from smokers with and without COPD [3-5], and also shown greater numbers of activated macrophages. Therefore, it is possible to speculate that, in addition to modulation of TCR expression and T-cell activation, the increased presence of IFN- $\gamma+$ cells may play a role in the immunomodulation of macrophage functions in COPD. IFN- $\gamma$ activates resting macrophages and induces the synthesis of an array of receptors for binding to pathogens, endothelia, degradative enzymes, transcription factors and cytokines involved in innate immunity [24]. Its immunoregulatory role also includes improved antigen presentation, enhanced killing of intracellular pathogens through activation of phagocytes and enhanced recruitment of activated macrophages [24, 25]. During disease exacerbations, activated macrophages can release IL-12 that, in turn, can stimulate T-cells and macrophages, resulting in even greater levels of IFN- $\gamma$ expression [8].

The importance of STAT4 activation and IFN- $\gamma$ production by macrophages in COPD is reinforced by the double-staining of phospho-(Y693)STAT4+ and CD68+ cells in the bronchial biopsies, the correlation between phospho-STAT4+ and IFN- $\gamma+$ cells, and the correlation between activated STAT4 and number of CD68+ cells in bronchial biopsies. STAT4 overexpression in macrophages is in agreement with recent data showing up-regulation of STAT4 in human IFN- $\gamma$ activated monocytes and synovial macrophages from patients with rheumatoid arthritis [26]. Importantly, transgenic mice 

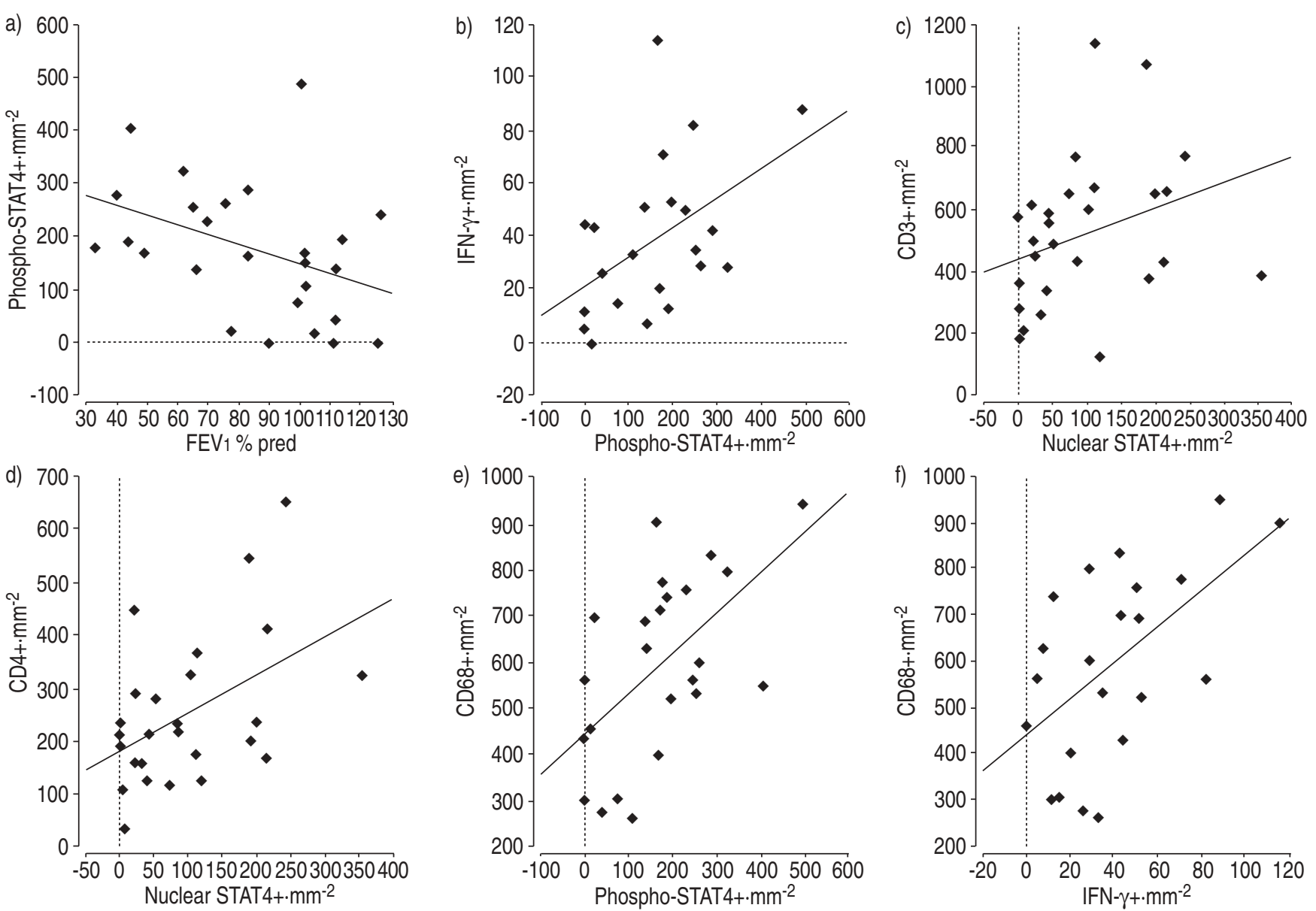

Fig. 3. - Regression analysis between a) forced expiratory volume in one second (FEV1) \% predicted and number of phospho-(Y-693)STAT4+ cells $(\mathrm{r}=0.46, \mathrm{p}=0.022)$, b) phospho-(Y-693)STAT4+ and interferon (IFN)- $\gamma+$ cells $(\mathrm{r}=0.45, \mathrm{p}=0.041)$, c) nuclear STAT4+ and CD3+ cells $(\mathrm{r}=0.42$, $\mathrm{p}=0.03), \mathrm{d})$ nuclear STAT4+ and CD4+ cells $(\mathrm{r}=0.40, \mathrm{p}=0.04)$, e) phospho-(Y-693)STAT4+ and CD68+ cells $(\mathrm{r}=0.54, \mathrm{p}=0.01)$, and $\mathrm{f})$ IFN- $\gamma+$ and CD68+ cells $(r=0.47, p=0.03)$ in the bronchial submucosa of all smokers. STAT4: signal transducer and activator of transcription 4.

which overexpress IFN- $\gamma$ develop emphysema via activation of phagocytes and increased matrix metalloproteinase-12 macrophage expression [27]. Macrophage inhibitory factor, released alongside IFN- $\gamma$, may also enhance macrophage tissue residency leading to increased lung destruction.

IFN- $\gamma$ inhibits collagen expression in fibroblasts [28] and decreases transforming growth factor- $\beta_{1}$ expression and collagen synthesis in mice $[29,30]$. The finding of increased IFN- $\gamma$ immunopositivity in the epithelium and submucosa of mild/moderate COPD patients invites speculation as to whether enhanced IFN- $\gamma$ expression may account for the lack of subepithelial basement membrane thickening in the bronchial biopsies in COPD, as compared to asthma [31]. Therefore, evidence for direct inhibitor effects of IFN- $\gamma$ on collagen synthesis and deposition in the subepithelial basement membrane of the bronchi of COPD patients needs further investigation.

T-bet can specify Th1 effector fate independently from IL12/STAT4 [10, 11], suggesting that STAT4 and T-bet can regulate IFN- $\gamma$ expression by distinct mechanisms. Downregulation of T-bet expression has been reported in human asthmatic airways [32], and studies in T-bet-knockout mice suggest that down-regulation of $\mathrm{T}$-bet is involved in the development of a Th2 response [32]. However, the current authors report here that $\mathrm{T}$-bet expression is not increased in either biopsies or BAL-derived lymphocytes from COPD patients in stable conditions. Therefore, it is possible that Tbet is less important in IFN- $\gamma$ production during stable disease. However, this does not rule out a role for T-bet during exacerbations of COPD.

The numbers of nuclear STAT4+ cells were significantly correlated with CD4+ cells in bronchial biopsies. This was confirmed by the prevalent double-staining of activated STAT4 in the CD4+ T-cell subset. In contrast, no significant correlation between STAT4 $+/ \mathrm{CD} 8+$ cells and IFN- $\gamma$ expression was found, despite the presence of some doublestained CD8+ cells. The prevailing view is that CD8+ cells are the most important T-cells in COPD [33]. However, these findings suggest that the increased numbers of CD4+ cells, compared with normal nonsmoking subjects, may play a significant role in terms of cell-activation and STAT4-overexpression in COPD. CD4+ T-cells are essential for ensuring the survival of $\mathrm{CD} 8+\mathrm{T}$-cells, priming their cytoxic responses, and for maintaining their memory [33], and even low numbers of activated CD4+ cells may be essential for the function of CD8+ cells in COPD. The current authors have shown that there is a clear STAT4-dependent Th1 differentiation in COPD. The data also suggest that either these cells have been activated and have differentiated into Th1 T-cells, or that the TCR on CD4+ cells has been engaged, thereby activating STAT4. Interestingly, in mice, STAT4 activation in CD4+ cells only occurs during TCR-induced IFN- $\gamma$ production [23]. The current authors speculate that if a similar mechanism is working in human T-cells, then the STAT4 activation observed in their patients may be the consequence of a preferential TCR engagement of an 

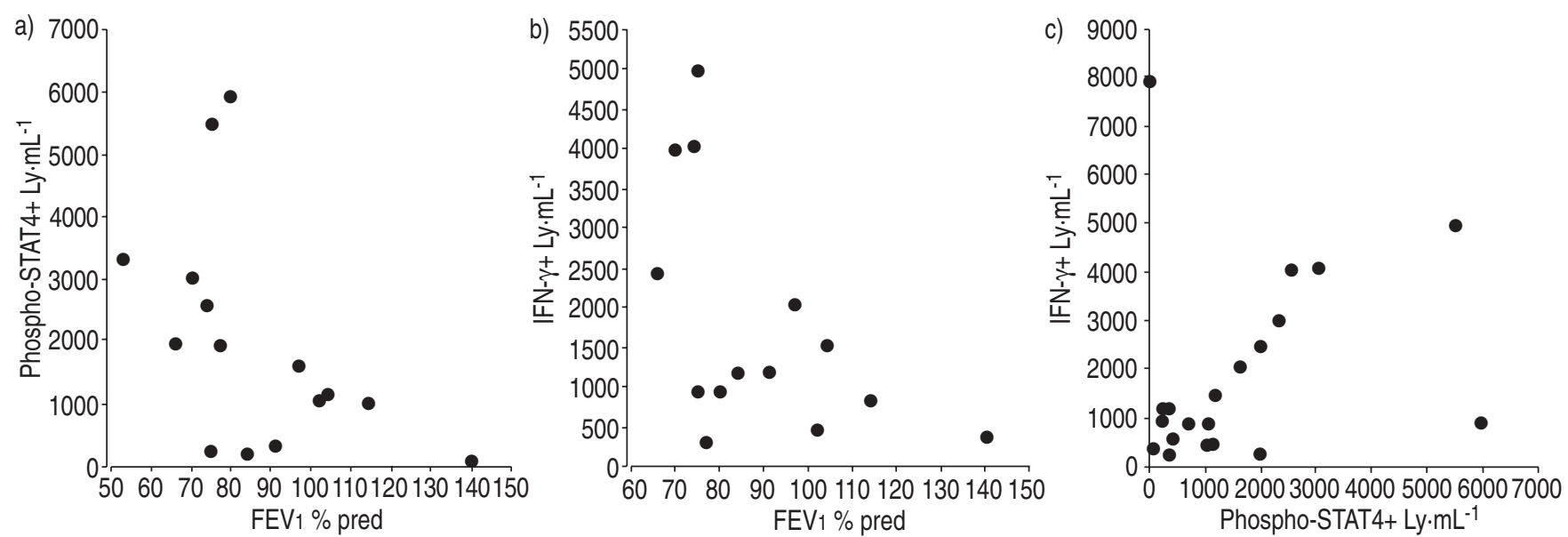

Fig. 4. - Regression analysis between a) forced expiratory volume in one second (FEV1) \% predicted and number of phospho-(Y-693)STAT4+ lymphocytes (Ly) $(\mathrm{r}=-0.62, \mathrm{p}=0.019)$, b) $\mathrm{FEV} 1 \%$ pred value and number of interferon (IFN)- $\gamma+\mathrm{Ly}(\mathrm{r}=-0.58, \mathrm{p}=0.038)$, and $\mathrm{c})$ the number of phospho-(Y-693)STAT4+ and IFN $\gamma+$ Ly $(r=0.57, \mathrm{p}=0.040)$ in the bronchoalveolar lavage of all smokers. STAT4: signal transducer and activator of transcription 4.

unknown antigen, and that COPD may be considered an autoimmune disease.

The current authors have also shown that increasing expression of activated STAT4 and IFN- $\gamma$ is correlated with decreasing lung function. These changes in lung function may reflect the increase in activated infiltrating cells, such as CD4+/CD8+ T-cells and macrophages, and the subsequent enhanced release of pro-inflammatory mediators, which eventually leads to the lung destruction seen in emphysema or possibly changes in the structure of the small airways, that were not investigated here. Importantly, the presence of $\mathrm{T}$ cells and macrophages within the alveoli is associated with loss of alveolar tissue [34]. An increase in CD4+ cells has previously been reported in COPD by НАTтOTUWA et al. [35], who also showed that inhaled glucocorticoids (ICS) prevent a rise in CD4+ cells in the bronchial mucosa over 3 months, and this may account for the improvement in symptom control and exacerbations in these subjects. ICS did not improve lung function in this study [35] and the presence of increased CD4+ cells was hypothesised to be due to subclinical exacerbations. Intriguingly, none of the patients in the current study were on ICS.

In conclusion, in this study the authors have shown enhanced immunoreactivity for IFN- $\gamma$ and STAT4 in bronchial biopsies, and increased immunoreactivity for STAT4 in BAL-derived lymphocytes of COPD patients. Overexpression of STAT4 was associated with the presence of IFN- $\gamma$, and also correlates with the degree of airflow limitation in smokers.

This study suggests that stable mild/moderate chronic obstructive pulmonary disease is associated with an active T-helper 1 cell/type-1 cytotoxic T-cell inflammatory response, leading to interferon- $\gamma$ production dependent from activation of signal transducer and activator of transcription 4 . The current data show that not only T-lymphocytes, but also activated macrophages, can participate in this immunological response.

\section{References}

1. Pauwels RA, Buist AS, Ma P, Jenkins CR, Hurd SS. Global strategy for the diagnosis, management, and prevention of chronic obstructive pulmonary disease: National Heart, Lung, and Blood Institute and World Health Organization global initiative for chronic obstructive lung disease (GOLD): executive summary. Respir Care 2001; 46: 798-825.
2. Barnes PJ. Chronic obstructive pulmonary disease. $N$ Engl J Med 2000; 343: 269-280.

3. Saetta M, Turato G, Maestrelli P, Mapp CE, Fabbri LM. Cellular and structural bases of chronic obstructive pulmonary disease. Am J Respir Crit Care Med 2001; 163: 1304 1309.

4. Di Stefano A, Capelli A, Lusuardi M, et al. Decreased T lymphocyte infiltration in bronchial biopsies of subjects with severe chronic obstructive pulmonary disease. Clin Exp Allergy 2001; 31: 893-902.

5. Saetta M, Mariani M, Panina-Bordignon $\mathrm{P}$, et al. Increased expression of the chemokine receptor CXCR3 and its ligand CXCL10 in peripheral airways of smokers with chronic obstructive pulmonary disease. Am J Respir Crit Care Med 2002; 165: 1404-1409.

6. Panina-Bordignon $\mathrm{P}$, Papi A, Mariani M, et al. The C-C chemokine receptors CCR 4 and CCR8 identify airway T cells of allergen-challenged atopic asthmatics. J Clin Invest 2001; 107: $1357-1364$

7. Sallusto F, Lanzavecchia A. Understanding dendritic cell and T-lymphocyte traffic through the analysis of chemokine receptor expression. Immunol Rev 2000; 177: 134-140.

8. Agnello D, Lankford CS, Bream J, et al. Cytokines and transcription factors that regulate $\mathrm{T}$ helper cell differentiation: new players and new insights. J Clin Immunol 2003; 23: 147-161.

9. Bacon CM, Petricoin EF 3rd, Ortaldo JR, et al. Interleukin 12 induces tyrosine phosphorylation and activation of STAT4 in human lymphocytes. Proc Natl Acad Sci USA 1995; 92: 7307-7311.

10. Mullen AC, High FA, Hutchins AS, et al. Role of T-bet in commitment of TH1 cells before IL-12-dependent selection. Science 2001; 292: 1907-1910.

11. Szabo SJ, Kim ST, Costa GL, Zhang X, Fathman CG, Glimcher LH. A novel transcription factor, T-bet, directs Th1 lineage commitment. Cell 2000; 100: 655-669.

12. Roca J, Burgos F, Sunyer J, et al. References values for forced spirometry. Group of the European Community Respiratory Health Survey. Eur Respir J 1998; 11: 1354-1362.

13. Capelli A, Di Stefano A, Gnemmi I, et al. Increased MCP-1 and MIP-1beta in bronchoalveolar lavage fluid of chronic bronchitics. Eur Respir J 1999; 14: 160-165.

14. Lim S, Groneberg D, Fischer A, et al. Expression of heme oxygenase isoenzymes 1 and 2 in normal and asthmatic airways: effect of inhaled corticosteroids. Am J Respir Crit Care Med 2000; 162: 1912-1918.

15. Di Stefano A, Capelli A, Lusuardi M, et al. Severity of 
airflow limitation is associated with severity of airway inflammation in smokers. Am $J$ Respir Crit Care Med 1998; 158: 1277-1285.

16. Ito K, Lim S, Caramori G, Chung KF, Barnes PJ, Adcock IM. Cigarette smoking reduces histone deacetylase 2 expression, enhances cytokine expression, and inhibits glucocorticoid actions in alveolar macrophages. FASEB $J$ 2001; 15: $1110-1112$.

17. Caramori G, Lim S, Ito K, et al. Expression of GATA family of transcription factors in T-cells, monocytes and bronchial biopsies. Eur Respir J 2001; 18: 466-473.

18. Di Stefano A, Caramori G, Oates $\mathrm{T}$, et al. Increased expression of nuclear factor- $\kappa \mathrm{B}$ in bronchial biopsies from smokers and patients with COPD. Eur Respir J 2002; 20: 556-563.

19. Adcock IM, Caramori G. Cross-talk between pro-inflammatory transcription factors and glucocorticoids. Immunol Cell Biol 2001; 79: 376-384.

20. Kaplan MH, Sun YL, Hoey T, Grusby MJ. Impaired IL-12 responses and enhanced development of Th2 cells in Stat4deficient mice. Nature 1996; 382: 174-177.

21. Thierfelder WE, van Deursen JM, Yamamoto $\mathrm{K}$, et al. Requirement for Stat4 in interleukin-12-mediated responses of natural killer and T cells. Nature 1996; 382: 171-174.

22. Rogge L, D'Ambrosio D, Biffi M, et al. The role of Stat4 in species-specific regulation of Th cell development by type I IFNs. J Immunol 1998; 161: 6567-6574.

23. Carter LL, Murphy KM. Lineage-specific requirement for signal transducer and activator of transcription (Stat) 4 in interferon gamma production from CD4(+) versus CD8(+) T cells. J Exp Med 1999; 189: 1355-1360.

24. Gallin JI, Farber JM, Holland SM, Nutman TB. Interferongamma in the management of infectious diseases. Ann Intern Med 1995; 123: 216-224.

25. Antoniou KM, Ferdoutsis E, Bouros D. Interferons and their application in the diseases of the lung. Chest 2003; 123 : 209-216.

26. Frucht DM, Aringer M, Galon J, et al. Stat4 is expressed in activated peripheral blood monocytes, dendritic cells, and macrophages at sites of Th1-mediated inflammation. J Immunol 2000; 164: 4659-4664.

27. Wang Z, Zheng $\mathrm{T}$, Zhu Z, et al. Interferon gamma induction of pulmonary emphysema in the adult murine lung. $J$ Exp Med 2000; 192: 1587-1600.

28. Jaffe HA, Gao Z, Mori Y, Li L, Varga J. Selective inhibition of collagen gene expression in fibroblasts by an interferongamma transgene. Exp Lung Res 1999; 25: 199-215.

29. Ulloa L, Doody J, Massague J. Inhibition of transforming growth factor-beta/SMAD signalling by the interferongamma/STAT pathway. Nature 1999; 397: 710-713.

30. Granstein RD, Murphy GF, Margolis RJ, Byrne MH, Amento EP. Gamma-interferon inhibits collagen synthesis in vivo in the mouse. J Clin Invest 1987; 79: 1254-1258.

31. Davies DE, Wicks J, Powell RM, Puddicombe SM, Holgate ST. Airway remodeling in asthma: new insights. J Allergy Clin Immunol 2003; 111: 215-225.

32. Finotto S, Neurath MF, Glickman JN, et al. Development of spontaneous airway changes consistent with human asthma in mice lacking T-bet. Science 2002; 295: 336-338.

33. Cosio MG, Majo J, Cosio MG. Inflammation of the airways and lung parenchyma in COPD: role of T cells. Chest 2002; 121: Suppl. 5, 160S-165S

34. Finkelstein R, Fraser RS, Ghezzo H, Cosio MG. Alveolar inflammation and its relation to emphysema in smokers. $\mathrm{Am}$ J Respir Crit Care Med 1995; 152: 1666-1672.

35. Hattotuwa KL, Gizycki MJ, Ansari TW, Jeffery PK, Barnes NC. The effects of inhaled fluticasone on airway inflammation in chronic obstructive pulmonary disease: a doubleblind, placebo-controlled biopsy study. Am J Respir Crit Care Med 2002; 165: 1592-1596. 